\title{
Control of Listeria monocytogenes in whole milk using antimicrobials applied individually and in combination
}

\author{
Sarah M. Kozak, ${ }^{*}$ Stephanie R. B. Brown, ${ }^{*}$ Yustyna Bobak, $†$ and Dennis J. D’Amico*1 \\ *Department of Animal Science, and \\ †Department of Molecular and Cell Biology, University of Connecticut, Storrs 06269
}

\begin{abstract}
Dairy product recalls and dairy-related illnesses are often the result of contamination with Listeria monocytogenes, which can occur throughout the dairy production and supply chains. The use of antimicrobial compounds is one practical approach for controlling pathogen survival and growth in foods. The goal of this study was to use fluid milk as a model system to identify listeristatic or listericidal treatments that show promise for application in fluid milk and for further evaluation in other dairy products (e.g., cheese). Caprylic acid (CA), $\varepsilon$-polylysine (EPL), hydrogen peroxide, lauric arginate (LAE), and sodium caprylate (SC) were added individually or in combination to whole milk inoculated with $L$. monocytogenes at $\sim 4 \log _{10} \mathrm{cfu} /$ $\mathrm{mL}$. Samples were stored at $7^{\circ} \mathrm{C}$ for $21 \mathrm{~d}$, and L. monocytogenes counts were determined weekly. Inhibitory concentrations of LAE $(800 \mathrm{mg} / \mathrm{L})$ and EPL (100-400 $\mathrm{mg} / \mathrm{L})$, as well as SC and CA (3,200 mg/L each), were identified. The addition of EPL at $800 \mathrm{mg} / \mathrm{L}$ reduced $L$. monocytogenes counts by $>3 \log _{10} \mathrm{cfu} / \mathrm{mL}$ from initial inoculation levels after $21 \mathrm{~d}$. Addition of hydrogen peroxide to milk reduced counts by $>3 \log _{10} \mathrm{cfu} / \mathrm{mL}$ from initial inoculation within $24 \mathrm{~h}(400$ and $800 \mathrm{mg} / \mathrm{L})$ or by d $7(200 \mathrm{mg} / \mathrm{L})$. Although the combinatory treatments of EPL + CA, EPL + LAE, and LAE + SC were characterized as indifferent, EPL $+\mathrm{SC}$ worked synergistically to reduce L. monocytogenes populations in milk over $21 \mathrm{~d}$. Overall, these data identify potential antimicrobial treatments to control L. monocytogenes in milk and serve as a foundation for the continued development of antimicrobial controls for L. monocytogenes in dairy products.
\end{abstract}

Key words: Listeria monocytogenes, milk, antimicrobial, synergy

Received August 8, 2017.

Accepted October 31, 2017.

${ }^{1}$ Corresponding author: ddamico@uconn.edu

\section{INTRODUCTION}

The food-pathogen combination of dairy and Listeria monocytogenes was recently ranked fifth in terms of annual disease burden in the United States when considering the loss of quality adjusted life years (a measure of health-related quality of life) and cost of illness (Batz et al., 2012). Contamination of dairy products with $L$. monocytogenes can occur throughout the food production and supply chains (Almeida et al., 2013) and outbreaks have been linked to both pasteurized and unpasteurized milk and milk products (CDC, 2017). According to the Centers for Disease Control and Prevention's Foodborne Outbreak Online Database (CDC, 2017), 18 reported outbreaks of listeriosis were linked to dairy products between 2003 and 2015, resulting in 166 illnesses, 130 hospitalizations, and 22 deaths. Thirteen of these outbreaks were linked to cheese and ice cream milkshakes produced from pasteurized milk as the result of postpasteurization cross-contamination (CDC, 2017). Because contaminated milk can be consumed directly or used in the manufacture of dairy products, there is a continuous need to identify methods to inhibit and inactivate L. monocytogenes. Milk also serves as a model food system to assess antimicrobial activity in the presence of interfering compounds including proteins and lipids (Chen and Zhong, 2017).

The use of antimicrobial compounds is a practical approach for controlling pathogen survival and growth in foods. According to US Food and Drug Administration (FDA) guidance on the control of L. monocytogenes in ready-to-eat foods, a listeristatic formulation that combines one or more antimicrobial substances is generally considered to be effective as a process control if growth studies that include samples at various points during product shelf life show an increase of $<1 \log _{10}$ cycle over 2 or more time intervals (e.g., days, weeks, and so on, based on sampling plan) in the number of $L$. monocytogenes during replicate trials with the food of interest (FDA, 2017b). Several antimicrobials generally recognized as safe (GRAS) by the FDA including caprylic acid (CA; FDA, 2015), hydrogen peroxide (HP; 
FDA, 2015), lauric arginate (LAE; FDA, 2005a,b), and $\varepsilon$-polylysine (EPL; FDA, 2011) have demonstrated efficacy in controlling $L$. monocytogenes under varying experimental conditions (Luchansky et al., 2005; Amrouche et al., 2010; Kozak et al., 2017), including applications in milk (Romanova et al., 2002; Geornaras et al., 2007; Ma et al., 2013) and cheese (Soni et al., 2010; Gadotti et al., 2014). Limited data are available on the efficacy of sodium caprylate (SC) against L. monocytogenes (Kozak et al., 2017), but several fatty acid derivatives including SC have demonstrated antimicrobial effects against gram-positive bacteria (Kabara et al., 1972; Nair et al., 2004).

The application of antimicrobials in foods can be affected by cost, regulatory limits, and potential changes to sensory properties (Nuñez de Gonzalez et al., 2006; Gadotti et al., 2014; Smith et al., 2015). The use of combinations of antimicrobials that work additively or synergistically to inhibit or inactivate $L$. monocytogenes can potentially enhance antimicrobial efficacy while allowing for reductions in individual usage concentrations (Kozak et al., 2017). Despite evidence of antimicrobial efficacy when compounds are used alone, the effect of potential synergistic combinations of antimicrobials in milk and other complex food matrices remains under investigated. To date, data on the efficacy of antimicrobials and their combinations in milk are scant and do not typically consider the potential shelf life of milk (Gaysinsky et al., 2007; Shah et al., 2013), which can extend beyond $21 \mathrm{~d}$ with little to no sensory defects (Ma et al., 2000). Determining the effectiveness of antimicrobial treatments in milk during cold storage also informs their potential use in other dairy products such as ice cream and fresh cheese. Therefore, the goal of this study was to use fluid milk as a model system to identify listeristatic or listericidal treatments that show promise for application in fluid milk and for further evaluation in other dairy products (e.g., cheese). More specifically, the objectives of this study were to (1) determine the efficacy of antimicrobial compounds used alone and in combination to control the growth of L. monocytogenes in whole milk throughout $21 \mathrm{~d}$ of storage at $7^{\circ} \mathrm{C}$ and (2) to characterize combinations as antagonistic, indifferent, additive, or synergistic.

\section{MATERIALS AND METHODS}

\section{Bacterial Strains, Growth Conditions, and Inoculum Preparation}

A cocktail of $8 \mathrm{~L}$. monocytogenes strains representing a diversity of subtypes and sources including those associated with outbreaks linked to dairy products was prepared as previously described (Kozak et al., 2017).
The cocktail was serially diluted in Butterfield's phosphate buffer (BPB), pelleted through centrifugation (15 min, 4,000 $\times g$ at $4^{\circ} \mathrm{C}$; Thermo Scientific Sorvall Legend X1R, Thermo Fisher Scientific, Waltham, MA), and re-suspended in UHT pasteurized whole milk (Parmalat, Parma, Italy). Working volumes of $25 \mathrm{~mL}$ of UHT milk in 50-mL conical tubes (Fisher Scientific International Inc., Hampton, NH) were then inoculated with the L. monocytogenes suspension to the target count of $\sim 4 \log _{10} \mathrm{cfu} / \mathrm{mL}$ for use in the assays below. Viable numbers of $L$. monocytogenes in suspension were verified by enumeration after serial dilution in BPB, spread-plating on brain heart infusion agar (BBL, Becton Dickinson, Franklin Lakes, NJ), and incubating plates at $37 \pm 1^{\circ} \mathrm{C}$ for 24 to $48 \mathrm{~h}$.

\section{Preparation of Antimicrobial Solutions}

Working antimicrobial stock solutions of CA (Sigma Aldrich, St. Louis, MO), EPL (San Keeper \#381; SanEi Gen FFI Inc., New York, NY), HP (30\%, Acros Organic, Pittsburgh, PA), LAE (Cytoguard LA2X, A+B Ingredients, Fairfield, NJ), and SC (Sigma Aldrich) were prepared in sterile deionized water. Caprylic acid, $\mathrm{SC}$, and LAE stocks were stored at room temperature, whereas EPL and HP were stored in the dark at $4^{\circ} \mathrm{C}$. Stock solutions were vortexed vigorously before use to ensure homogeneity and added to milk to achieve target concentrations $(\mathrm{mg} / \mathrm{L})$ of the active compound in milk, accounting for the concentrations in the original antimicrobial product.

\section{Decomposition of Hydrogen Peroxide}

The decomposition of HP at the treatment concentrations (100 to $800 \mathrm{mg} / \mathrm{L}$ ) in whole milk with and without L. monocytogenes ( $4 \log _{10} \mathrm{cfu} / \mathrm{mL}$ ) during storage at $7^{\circ} \mathrm{C}$ was determined by measuring $\mathrm{HP}$ concentrations daily throughout storage using commercially available colorimetric peroxide test strips (1-3-10-30-100 mg/L; EMD Chemicals Inc., Gibbstown, NJ). When the color was between break points, the break point values were averaged (e.g., between 10 and $30=20 \mathrm{mg} / \mathrm{L}$ ) and the mean value was recorded.

\section{Time-Kill Assays}

The efficacy of antimicrobial compounds used alone and in combination against L. monocytogenes in milk was determined using a standard broth dilution assay (Andrews, 2001). Experiments were conducted in UHT whole milk to eliminate background microbiota as a variable for this screening and to account for the 
potential effect of milkfat, which has been shown to reduce the efficacy of antimicrobials such as LAE (Soni et al., 2010). Antimicrobial stock solutions were serially diluted in sterile deionized water and $100-\mu \mathrm{L}$ aliquots of each dilution were added to $25 \mathrm{~mL}$ of UHT milk to achieve the desired antimicrobial concentrations. Experimental treatments as listed in Table 1 were selected based on previous reports in the literature where available, while considering the potential effect of the food matrix and temperature (Lingbeck et al., 2014). Combination treatments were selected based on reported additive and synergistic interactions (Kozak et al., 2017) and were formulated to contain antimicrobials at $0.5 \times$ their inhibitory concentration in milk to observe the effect of combinations (Ma et al., 2013; Shi et al., 2017). Inoculated UHT milk samples without antimicrobials were included as positive controls, uninoculated UHT milk containing each of the antimicrobial treatments individually served as antimicrobial controls, and uninoculated UHT milk containing no antimicrobial served as a negative control. The $\mathrm{pH}$ of each treatment was measured following the addition of antimicrobials (Accumet AB150, Fisher Scientific International Inc.). Samples were stored for $21 \mathrm{~d}$ at $7^{\circ} \mathrm{C}$ to mimic retail storage and mild temperature abuse along the food supply chain (Kennedy et al., 2005). Samples were serially diluted in BPB and spread onto brain heart infusion agar before the addition of antimicrobial compounds (initial inoculation) and on d 1, 7, 14, and 21 following antimicrobial addition. Counts of L. monocytogenes were determined following incubation at $37^{\circ} \mathrm{C}$ for 24 to $48 \mathrm{~h}$.

\section{Data Analysis}

All assays were performed independently in triplicate using independently propagated cultures on 3 different days, with 2 technical replicates per treatment per sampling time point. Fresh working antimicrobial stock solutions were prepared for each biological replicate. Counts below the detection limit $(\geq 1 \mathrm{cfu} / \mathrm{mL})$ were recorded as $0 \mathrm{cfu} / \mathrm{mL}$. Counts from technical replicates were averaged for each trial $(\mathrm{n}=3)$. Mean bacterial counts were $\log _{10}$ transformed for statistical analysis. Data were analyzed using the PROC MIXED procedure of SAS 9.4 (SAS Institute Inc., Cary, NC) to determine the effects of treatment, time, and treatment $\times$ time interactions on L. monocytogenes counts. Pairwise comparisons including $\mathrm{pH}$ values were performed using LSMEANS with the Tukey-Kramer method. The effects of the presence/absence of L. monocytogenes, time, and the presence/absence of L. monocytogenes over time on hydrogen peroxide concentrations in milk were determined using the GLM procedure for repeated measures (SPSS for Windows, version 24, SPSS Inc., Chicago, IL). Significance was defined at $P<0.05$.

Inhibitory and bactericidal activity were defined as $<1 \log _{10} \mathrm{cfu} / \mathrm{mL}$ of growth and $\geq 3 \log _{10} \mathrm{cfu} / \mathrm{mL}$ reduction in L. monocytogenes counts at a given time point compared with the initial inoculum level, respectively (NACMCF, 2010; FDA, 2017b). Antimicrobial combinations were characterized based on common established criteria (NCCLS, 1999; Steenbergen et al., 2009; Shi et al., 2017) modified for longer-term experiments in food. Briefly, combinations resulting in counts $\geq 2$ $\log _{10} \mathrm{cfu} / \mathrm{mL}$ lower than the most active constituent alone after $21 \mathrm{~d}$ were defined as synergistic. Combinations were considered additive if counts after $21 \mathrm{~d}$ were $<2$ but $>1 \log _{10} \mathrm{cfu} / \mathrm{mL}$ lower than those obtained using the most active constituent alone. Combinations with counts $<2 \log _{10}$ and $\geq 2 \log _{10} \mathrm{cfu} / \mathrm{mL}$ higher than the least active constituent alone were defined as indifferent and antagonistic, respectively.

\section{RESULTS AND DISCUSSION}

\section{Efficacy of Individual Antimicrobial Treatments}

Antimicrobial Activity of $C A$ and $S C$. Caprylic acid is currently GRAS at levels not to exceed current

Table 1. Antimicrobial treatments, concentrations, and resulting $\mathrm{pH}$ of sterile whole milk

\begin{tabular}{|c|c|c|}
\hline Treatment $^{1}$ & Concentration (mg/L) & $\mathrm{pH} \pm \mathrm{SD}$ \\
\hline Control & & $6.67 \pm 0.02$ \\
\hline \multirow[t]{4}{*}{$\mathrm{CA}$} & 400 & $6.61 \pm 0.09$ \\
\hline & 800 & $6.64 \pm 0.02$ \\
\hline & 1,600 & $6.36 \pm 0.04^{* * *}$ \\
\hline & 3,200 & $5.44 \pm 0.06^{* * *}$ \\
\hline \multirow[t]{4}{*}{ EPL } & 100 & $6.67 \pm 0.02$ \\
\hline & 200 & $6.71 \pm 0.01$ \\
\hline & 400 & $6.83 \pm 0.01^{* * *}$ \\
\hline & 800 & $6.78 \pm 0.04^{* *}$ \\
\hline \multirow[t]{4}{*}{ HP } & 100 & $6.66 \pm 0.01$ \\
\hline & 200 & $6.68 \pm 0.00$ \\
\hline & 400 & $6.68 \pm 0.01$ \\
\hline & 800 & $6.68 \pm 0.00$ \\
\hline \multirow[t]{4}{*}{ LAE } & 100 & $6.57 \pm 0.02^{*}$ \\
\hline & 200 & $6.53 \pm 0.02^{* * *}$ \\
\hline & 400 & $6.52 \pm 0.02^{* * *}$ \\
\hline & 800 & $6.53 \pm 0.02^{\text {*** }}$ \\
\hline \multirow[t]{4}{*}{$\mathrm{SC}$} & 400 & $6.72 \pm 0.01$ \\
\hline & 800 & $6.75 \pm 0.01$ \\
\hline & 1,600 & $6.74 \pm 0.03$ \\
\hline & 3,200 & $6.73 \pm 0.12$ \\
\hline $\mathrm{EPL}+\mathrm{SC}$ & $50+1,600$ & $6.70 \pm 0.02$ \\
\hline $\mathrm{EPL}+\mathrm{CA}$ & $50+1,600$ & $6.25 \pm 0.06^{* * *}$ \\
\hline $\mathrm{LAE}+\mathrm{SC}$ & $400+1,600$ & $6.64 \pm 0.05$ \\
\hline $\mathrm{EPL}+\mathrm{LAE}$ & $50+400$ & $6.65 \pm 0.01$ \\
\hline
\end{tabular}

${ }^{1}$ Treatments: $\mathrm{CA}=$ caprylic acid; $\mathrm{EPL}=\varepsilon$-polylysine; $\mathrm{HP}=$ hydrogen peroxide; $\mathrm{LAE}=$ lauric arginate; $\mathrm{SC}=$ sodium caprylate.

${ }^{*} \mathrm{pH}$ of treatment differs from control $(P<0.05) ; *^{*} \mathrm{pH}$ of treatment differs from control $(P<0.01)$; ${ }^{* * *} \mathrm{pH}$ of treatment differs from control $(P<0.001)$. 
good manufacturing practices, which result in maximum levels, as served, of $400 \mathrm{mg} / \mathrm{kg}$ for cheeses and $50 \mathrm{mg} /$ $\mathrm{kg}$ for frozen dairy desserts (FDA, 2017a). Addition to milk has yet to be added as an intended use. Neither compound is an approved ingredient according to the standards of identity for milk and cream (21 CFR 131), cheese and related cheese products (21 CFR 133), and frozen dairy desserts (21 CFR 135). However, addition of CA to nonstandardized products like soft cheeses would be allowed if used within the GRAS limits of $400 \mathrm{mg} / \mathrm{kg}$ or less. All concentrations of CA or SC in the present study inhibited L. monocytogenes growth in milk to $\leq 1 \log _{10} \mathrm{cfu} / \mathrm{mL}$ through $7 \mathrm{~d}$ of storage. However, only SC at 3,200 mg/L and CA at 1,600 and 3,200 $\mathrm{mg} / \mathrm{L}$ were inhibitory through the entire 21 -d storage period (Figures 1 and 2). The inhibitory concentration of $\mathrm{CA}$ in milk at $7^{\circ} \mathrm{C}(3,200 \mathrm{mg} / \mathrm{L})$ is similar to that reported in broth incubated at $37^{\circ} \mathrm{C}(3,250 \mathrm{mg} / \mathrm{L}$; Kozak et al., 2017) despite differences in the assay medium, temperature, and $\mathrm{pH}$. In contrast, the MIC for $\mathrm{SC}$ in milk $(3,200 \mathrm{mg} / \mathrm{L})$ was lower than that reported in broth (Kozak et al., 2017), suggesting that the milk matrix or lower temperature or both may enhance antimicrobial activity. We observed no significant difference between counts of L. monocytogenes on d 21 in milk containing $\mathrm{CA}$ or $\mathrm{SC}$ at $3,200 \mathrm{mg} / \mathrm{L}(P=1)$, suggesting these compounds have similar efficacy against $L$. monocytogenes in milk. Inhibitory concentrations of CA significantly reduced milk $\mathrm{pH}$, whereas all concentrations of SC increased milk pH (Table 1), which could affect potential future applications in milk and dairy foods where such changes in $\mathrm{pH}$ are not acceptable. Because both CA and SC have shown increased effectiveness in acidic environments (Kozak et al., 2017), they may be promising surface treatments to inhibit $L$. monocytogenes growth in acidified dairy products such as fresh cheese (e.g., Ricotta). Higher concentrations may be necessary to produce bactericidal effects. For example, Nair et al. (2004) reported significant reductions in L. monocytogenes counts $\left(\sim 2.7 \log _{10} \mathrm{cfu} / \mathrm{mL}\right)$ after $48 \mathrm{~h}$ at $8^{\circ} \mathrm{C}$ when $\mathrm{CA}$ was added to sterile whole milk at $50 \mathrm{~m} M(\sim 7,200 \mathrm{mg} / \mathrm{L}$; $\mathrm{pH} 5.4)$, whereas $25 \mathrm{mM}$ $(\sim 3,600 \mathrm{mg} / \mathrm{L} ; \mathrm{pH} 5.6)$ produced little change. However, addition of CA at these concentrations reduced milk $\mathrm{pH}$ and increases the risk of negative changes to consumer acceptability. For example, the addition of CA to fresh cheese curds during manufacture at $1.09 \mathrm{~g} /$ $\mathrm{kg}(1,090 \mathrm{mg} / \mathrm{kg})$ resulted in cheeses with significantly reduced consumer acceptability scores when compared with untreated and commercial controls (Lourenço et al., 2017).

Antimicrobial Activity of LAE. Lauric arginate is currently GRAS in the United Stated for use in certain animal-based foods as well as cheeses (e.g., curd and whey cheeses, cream, natural, grating, processed, spread, and dip cheeses) at levels up to 200

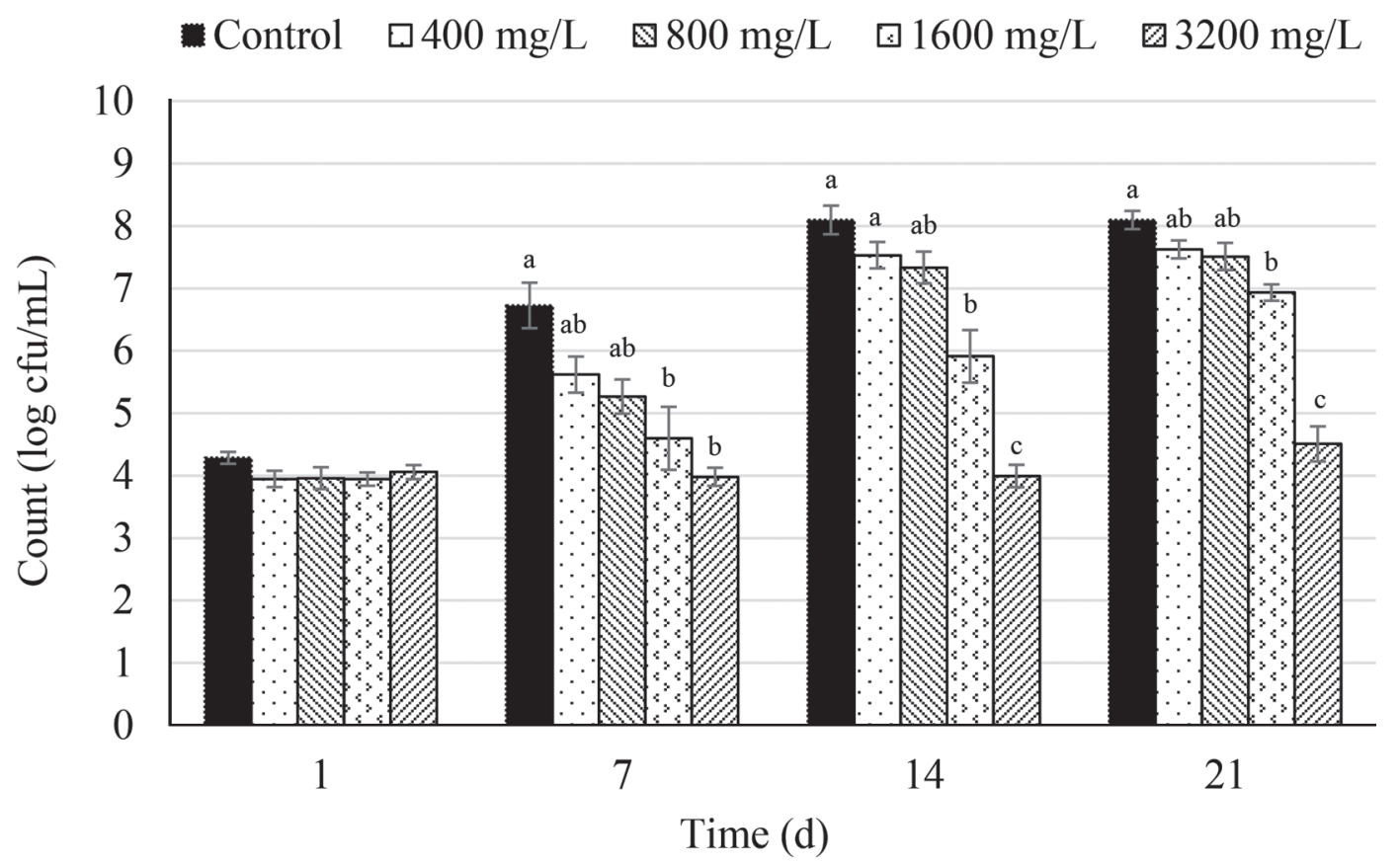

Figure 1. Change in Listeria monocytogenes counts (mean $\log _{10} \mathrm{cfu} / \mathrm{mL}$ of 3 replicates $\pm \mathrm{SEM}$ ) in sterile whole milk with caprylic acid when held at $7^{\circ} \mathrm{C}$. Columns with different letters within a time point differ $(P<0.05)$. 
$\mathrm{mg} / \mathrm{kg}$ (FDA, 2005a,b). Similar to CA, LAE is not an approved ingredient in standardized cheeses or other standardized dairy products but could be used in nonstandardized products like soft cheese. Though LAE is known to bind to anionic biopolymers naturally present within the mouth, which may lead to a perceived bitterness or astringency (Bonnaud et al., 2010), the use of LAE is not expected to negatively affect the aroma, flavor, texture, or overall acceptability of products like fresh soft cheese (Soni et al., 2010). Applications have been shown to inhibit a broad spectrum of foodborne pathogens over a wide $\mathrm{pH}$ range (3-7). Binding of LAE to the plasma membrane lipid bilayer can result in structural changes and interrupt metabolic processes thereby inhibiting cell proliferation (Rodriguez et al., 2004; EFSA, 2007). The addition of LAE to milk at 100, 200 , and $400 \mathrm{mg} / \mathrm{L}$ allowed for growth similar to that of the control throughout storage and we observed no significant differences in bacterial counts between these treatments at any time point (Figure 3). Treatments at $800 \mathrm{mg} / \mathrm{L}$ steadily reduced $L$. monocytogenes levels throughout storage with final counts reaching $1.68 \log _{10}$ $\mathrm{cfu} / \mathrm{mL}$ lower than the starting inoculum of $4.5 \log _{10}$ $\mathrm{cfu} / \mathrm{mL}$ and $\sim 5 \log _{10} \mathrm{cfu} / \mathrm{mL}$ less than the control on $\mathrm{d}$ 21 (Figure 3). All LAE treatments produced significant reductions in milk pH from 6.67 to $6.57-6.53$. Soni et al. (2010) reported inhibition of L. monocytogenes growth with LAE at concentrations as low as $400 \mathrm{mg} / \mathrm{L}$ in skim milk. The authors also observed that $800 \mathrm{mg} / \mathrm{L}$ of LAE reduced $L$. monocytogenes counts to undetectable levels in both skim and whole milk after $24 \mathrm{~h}$, which persisted throughout $15 \mathrm{~d}$ of storage at $4^{\circ} \mathrm{C}$. Similarly, Ma et al. (2013) found that $750 \mathrm{mg} / \mathrm{L}$ of LAE in $2 \%$ reduced fat skim milk at $32^{\circ} \mathrm{C}$ reduced L. monocytogenes Scott A by $6.20 \log _{10} \mathrm{cfu} / \mathrm{mL}$ after $24 \mathrm{~h}$. However, reductions of $\sim 2$ and $3 \log _{10} \mathrm{cfu} / \mathrm{mL}$ were reported after 24 and 48 $\mathrm{h}$, respectively, when the treatment temperature was reduced to $21^{\circ} \mathrm{C}$, suggesting that antimicrobial efficacy decreases with decreasing temperatures. Other studies have also demonstrated reductions in the antimicrobial activity of LAE at lower incubation temperatures (Lingbeck et al., 2014). Therefore, differences in results between studies may be attributed to differences in the commercial LAE products used, fat contents of milk, $L$. monocytogenes strains used, as well as time and temperature of the experiments. The effect of temperature, fat content, and other food components on the efficacy of LAE is also supported by a more than 100-fold increase in the inhibitory concentrations observed in refrigerated whole milk ( $\sim 800 \mathrm{mg} / \mathrm{L})$ compared with that reported for the same strains of $L$. monocytogenes in broth at $37^{\circ} \mathrm{C}(6.25 \mathrm{mg} / \mathrm{L}$; Kozak et al., 2017).

Antimicrobial Activity of EPL. $\varepsilon$-Polylysine is a polypeptide comprised of repeating lysine subunits that electrostatically adsorb onto the surface of, and interfere with, microbial cell membranes. As an anti-

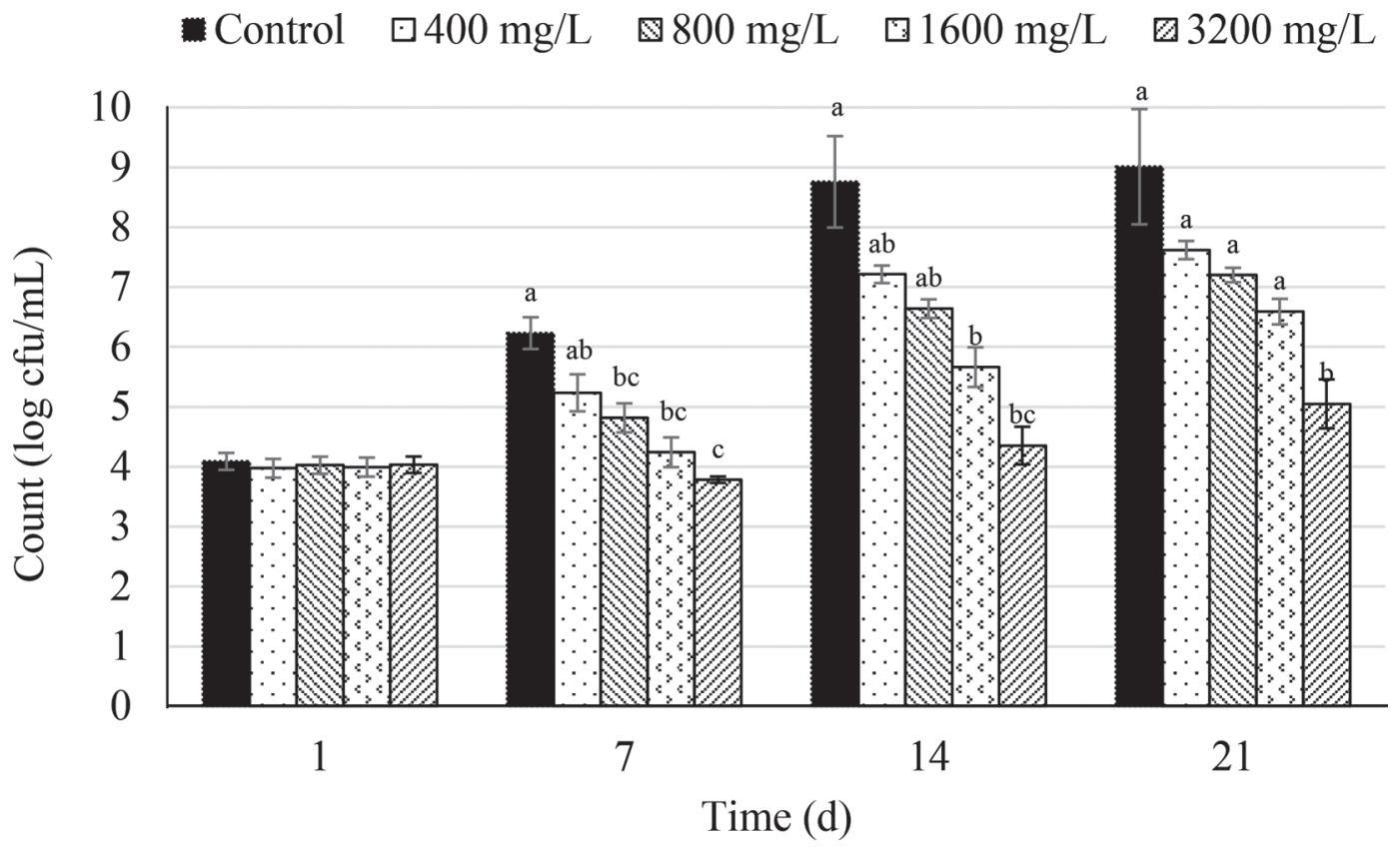

Figure 2. Change in Listeria monocytogenes counts (mean $\log _{10} \mathrm{cfu} / \mathrm{mL}$ of 3 replicates $\pm \mathrm{SEM}$ ) in sterile whole milk with sodium caprylate when held at $7^{\circ} \mathrm{C}$. Columns with different letters within a time point differ $(P<0.05)$. 


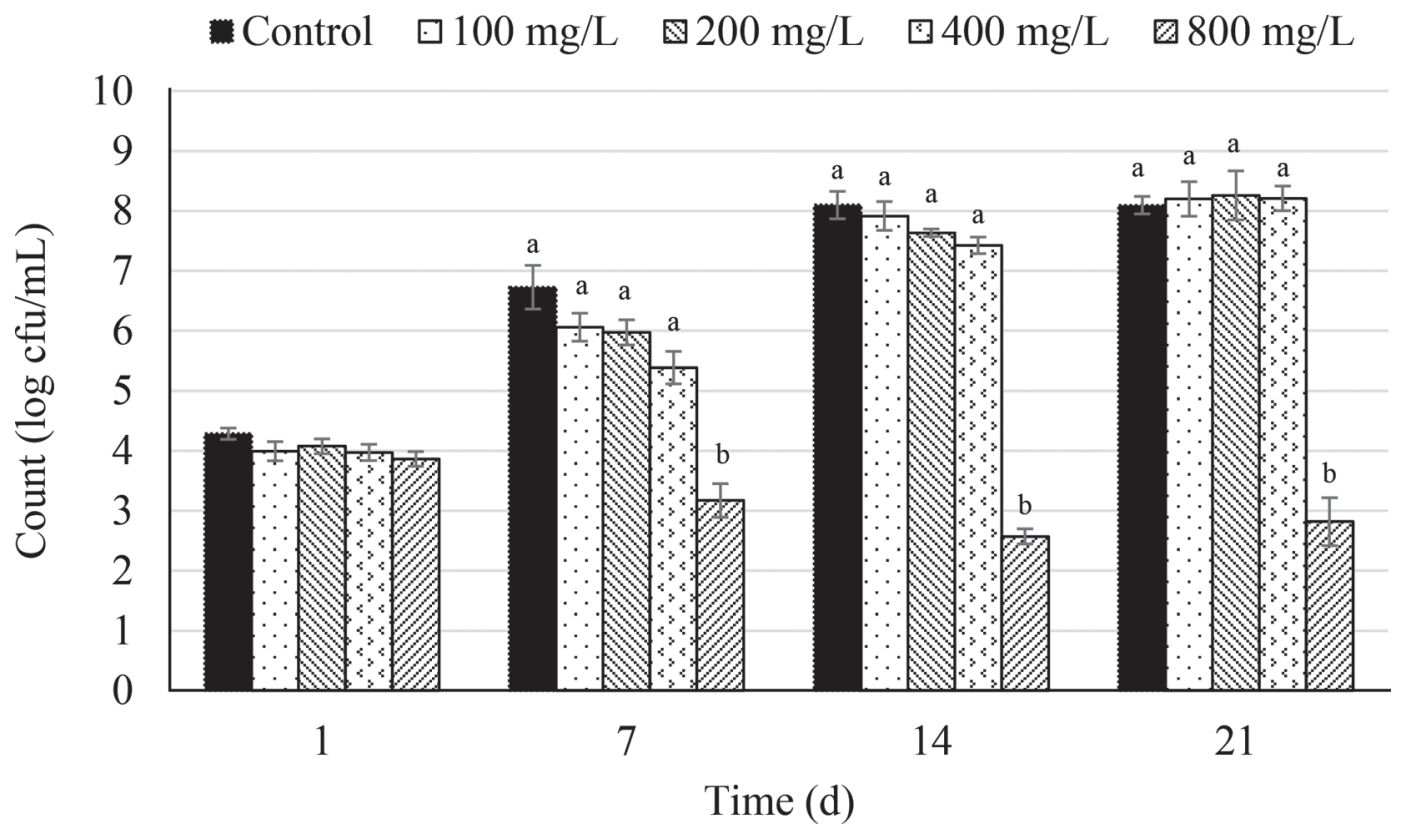

Figure 3. Change in Listeria monocytogenes counts (mean $\log _{10} \mathrm{cfu} / \mathrm{mL}$ of 3 replicates \pm SEM) in sterile whole milk with lauric arginate when held at $7^{\circ} \mathrm{C}$. Columns with different letters within a time point differ $(P<0.05)$.

microbial, EPL is effective against both gram-positive and gram-negative bacteria, as well as yeasts and mold (Shima et al., 1984; Yoshida and Nagasawa, 2003). The use of EPL as an antimicrobial in milk and dairy products is desirable owing to its solubility in water, efficacy at neutral $\mathrm{pH}$ and lower temperatures (Geornaras and Sofos, 2005), and limited organoleptic changes when applied to foods (Hiraki et al., 2003). In the present study, the addition of EPL at concentrations $\geq 400 \mathrm{mg} / \mathrm{L}$ slightly, but significantly $(P<0.001$ and $P=0.003$ for 400 and $800 \mathrm{mg} / \mathrm{L}$, respectively), increased milk $\mathrm{pH}$ (Table 1), consistent with previous reports (Geornaras et al., 2007). Counts resulting from $25 \mathrm{mg} / \mathrm{L}$ EPL treatments did not differ from control at any time point. Counts in the $50 \mathrm{mg} / \mathrm{L}$ treatments were lower than control on $\mathrm{d} 7(P=0.037)$ and $14(P$ $=0.018$ ), but similar by the final day of sampling. Concentrations of 100 and $200 \mathrm{mg} / \mathrm{L}$ of EPL inhibited the growth of $L$. monocytogenes through $21 \mathrm{~d}$ with counts in the $200 \mathrm{mg} / \mathrm{L}$ treatments lower than the starting inoculum of $4.78 \log _{10} \mathrm{cfu} / \mathrm{mL}(P<0.001)$ on $\mathrm{d} 21$ (Figure 4). Treatments at 400 and $800 \mathrm{mg} / \mathrm{L}$ resulted in a gradual decrease in pathogen counts over $21 \mathrm{~d}$ with $800 \mathrm{mg} / \mathrm{L}$ defined as bactericidal based the $3.33 \log _{10}$ $\mathrm{cfu} / \mathrm{mL}$ reduction from the initial inoculation. These results are similar to those reported by Geornaras et al. (2007) where L. monocytogenes counts were reduced to undetectable levels in diluted fat-free and whole milk with $200 \mathrm{mg} / \mathrm{L}$ of EPL after 6 d of storage. Bactericidal activity at the lower concentration of $200 \mathrm{mg} / \mathrm{L}$ may be attributed to dilution of potentially inhibitory milk components (i.e., fat and protein) in preparation of the milk extracts. The inhibitory concentration of EPL was $\sim 10$-fold higher in milk than that reported for broth at pH 7.4 (20 mg/L; Kozak et al., 2017) and is most likely attributed to the interaction of EPL with food components in milk. Potential interactions between LAE and EPL with negatively charged proteins (i.e., casein micelles) could reduce their ability to interact with target bacterial cells. Regardless, the results presented here identify EPL as a promising antimicrobial for use in milk and other dairy products. Currently, EPL has GRAS status for use in cream and various cheeses at a level up to $250 \mathrm{mg} / \mathrm{kg}$ in the United States (FDA, 2011) but is not an approved ingredient in standardized dairy products.

Antimicrobial Activity of HP and Its Decomposition in Milk. The use of HP is desirable owing to its decomposition into nontoxic byproducts and its long history of use as an antimicrobial in the dairy industry to preserve raw milk in the absence of refrigeration (Roundy, 1958). Direct addition of HP to raw milk at high concentrations (i.e., $900 \mathrm{mg} / \mathrm{L}$ ) has been shown to reduce total bacteria counts when held at $6^{\circ} \mathrm{C}$ or ambient temperature for $48 \mathrm{~h}$ (Martin et al., 2014). Hydrogen peroxide has also been shown to increase the lag phase of L. monocytogenes in skim milk held at $20^{\circ} \mathrm{C}$ (Siragusa and Johnson, 1989) and inhibit growth in raw milk held at 4 and $8^{\circ} \mathrm{C}$ (Gaya et al., 1991) when added at 0.25 to $0.3 \mathrm{mM}$ as part of the lactoperoxidase-thio- 
cyanate-HP system. Hydrogen peroxide has been shown to rapidly inactivate $L$. monocytogenes in broth over a range of concentrations at $37^{\circ} \mathrm{C}$ (Liu and Ream, 2008) and when added to sterilized milk at $495 \mathrm{mg} / \mathrm{L}$ and stored at $4^{\circ} \mathrm{C}$ (Dominguez et al., 1987). A concentration of $100 \mathrm{mg} / \mathrm{L}$ inhibited growth of L. monocytogenes over $21 \mathrm{~d}$ at $7^{\circ} \mathrm{C}$ in the present study with an overall $2.5 \log _{10}$ $\mathrm{cfu} / \mathrm{mL}$ reduction from initial inoculation by the end of storage reaching $1.49 \pm 0.93 \log _{10} \mathrm{cfu} / \mathrm{mL}$. Concentrations of 400 and $800 \mathrm{mg} / \mathrm{L}$ were bactericidal within 24 $\mathrm{h}$, and $200 \mathrm{mg} / \mathrm{L}$ reduced counts by more than $3 \log _{10}$ $\mathrm{cfu} / \mathrm{mL}$ from initial inoculation $\left(4.01 \log _{10} \mathrm{cfu} / \mathrm{mL}\right)$ by d 7 of storage (Figure 5). Counts remained below the limit of detection $(\geq 1 \mathrm{cfu} / \mathrm{mL})$ from d 7 through d 21 for treatments of 200,400 , and $800 \mathrm{mg} / \mathrm{mL}$.

Decomposition assays demonstrate the gradual degradation of $\mathrm{HP}$ during storage over $21 \mathrm{~d}$ at $7^{\circ} \mathrm{C}$. Table 2 shows the change in HP concentration over time for the initial concentrations ( $\mathrm{d} 0$ ) and odd sampling days (i.e., $1,3,5$, and so on). Only data for samples containing L. monocytogenes are shown because the presence of $L$. monocytogenes was only found to significantly affect the decomposition of HP over time when added at 800 $\mathrm{mg} / \mathrm{L}(P=0.036)$. Hydrogen peroxide concentrations in the $100 \mathrm{mg} / \mathrm{L}$ treatments were determined to be 30 $\mathrm{mg} / \mathrm{L}$ within $48 \mathrm{~h}$ and remained at $1 \pm 1 \mathrm{mg} / \mathrm{L}$ from d 8 through 21 (Table 2). Measurements from treatment concentrations of 200,400 , and $800 \mathrm{mg} / \mathrm{L}$ remained at $\geq 100 \mathrm{mg} / \mathrm{L}$ through $\mathrm{d} 2,3$, and 4, respectively.
Concentrations gradually declined in these treatments and remained in the 10 to $30 \mathrm{mg} / \mathrm{L}$ range through the remaining storage period. The decomposition in UHT whole milk reported here differs from that observed in raw milk by Martin et al. (2014), where the predicted probability of detecting HP in raw milk after $48 \mathrm{~h}$ of storage at 6 or $21^{\circ} \mathrm{C}$ using peroxide test strips was quite low at most concentrations. The authors concluded that this, when combined with the absence of continued decrease in bacterial numbers, suggests that the HP had decomposed. Based on the time-kill results in the present study, it is likely that the higher concentrations fully inactivated $L$. monocytogenes populations during these initial time points with residual peroxide preventing any potential recovery and growth as observed in the $100 \mathrm{mg} / \mathrm{L}$ treatment.

According to the Standards of Identity for cheese, HP is approved for use in certain varieties of cheese in the United States (i.e., Cheddar, Colby, washed or soaked curd, granular or stirred curd, Swiss, and Emmentaler) when added at levels up to $500 \mathrm{mg} / \mathrm{L}$ followed by neutralization with catalase (21 CFR 133; FDA, 2016). Treatments within this limit were effective and did not alter milk pH (Table 1). Although these treatments were effective at reducing levels of $L$. monocytogenes in fluid milk, evidence indicates that HP applied as low as $10 \mathrm{mg} / \mathrm{L}$ may inhibit acid production by starter cultures even after residual HP is neutralized using catalase (Subramanian and Olson, 1968),

\section{- Control $\square 25 \mathrm{mg} / \mathrm{L} \otimes 50 \mathrm{mg} / \mathrm{L} \otimes 100 \mathrm{mg} / \mathrm{L} \otimes 200 \mathrm{mg} / \mathrm{L}$ 曰 $400 \mathrm{mg} / \mathrm{L} \square 800 \mathrm{mg} / \mathrm{L}$}

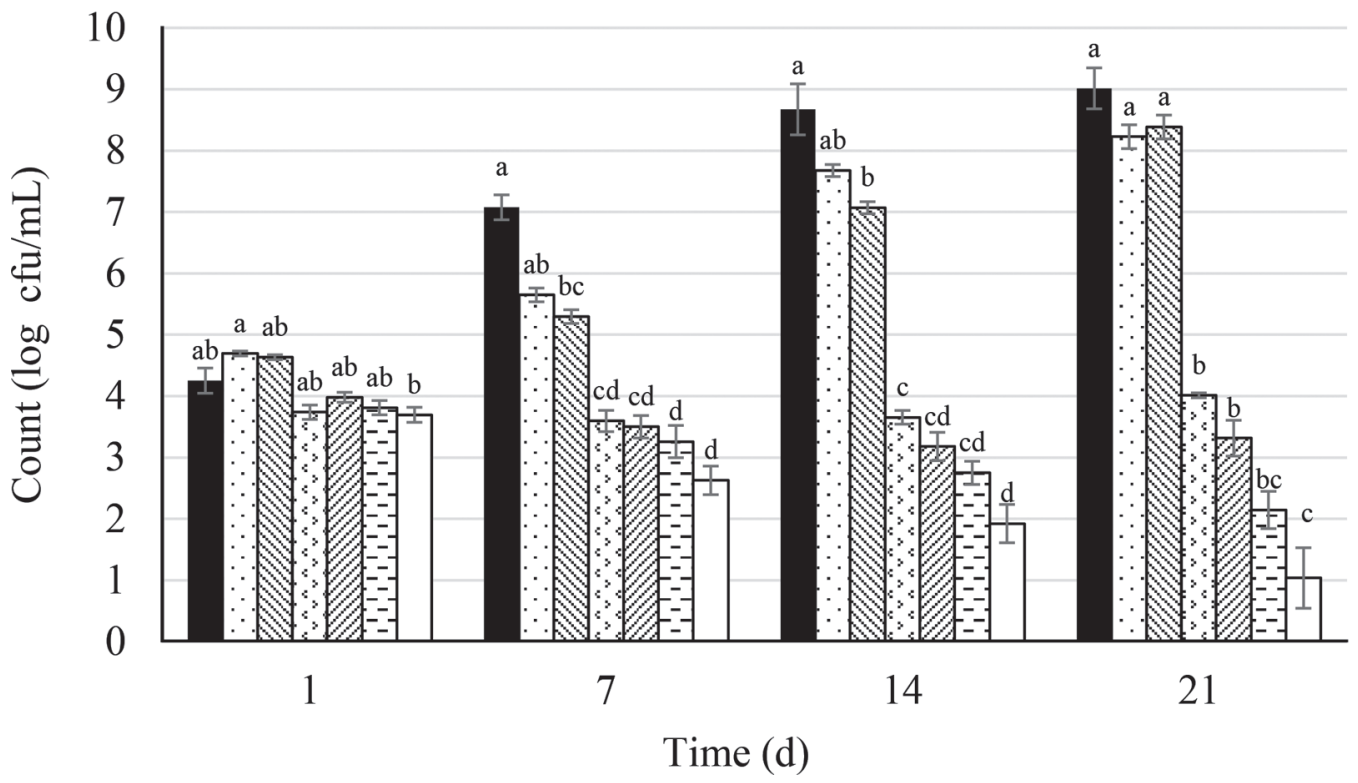

Figure 4. Change in Listeria monocytogenes counts (mean $\log _{10} \mathrm{cfu} / \mathrm{mL}$ of 3 replicates $\pm \mathrm{SEM}$ ) in sterile whole milk with $\varepsilon$-polylysine when held at $7^{\circ} \mathrm{C}$. Columns with different letters within a time point differ $(P<0.05)$. 


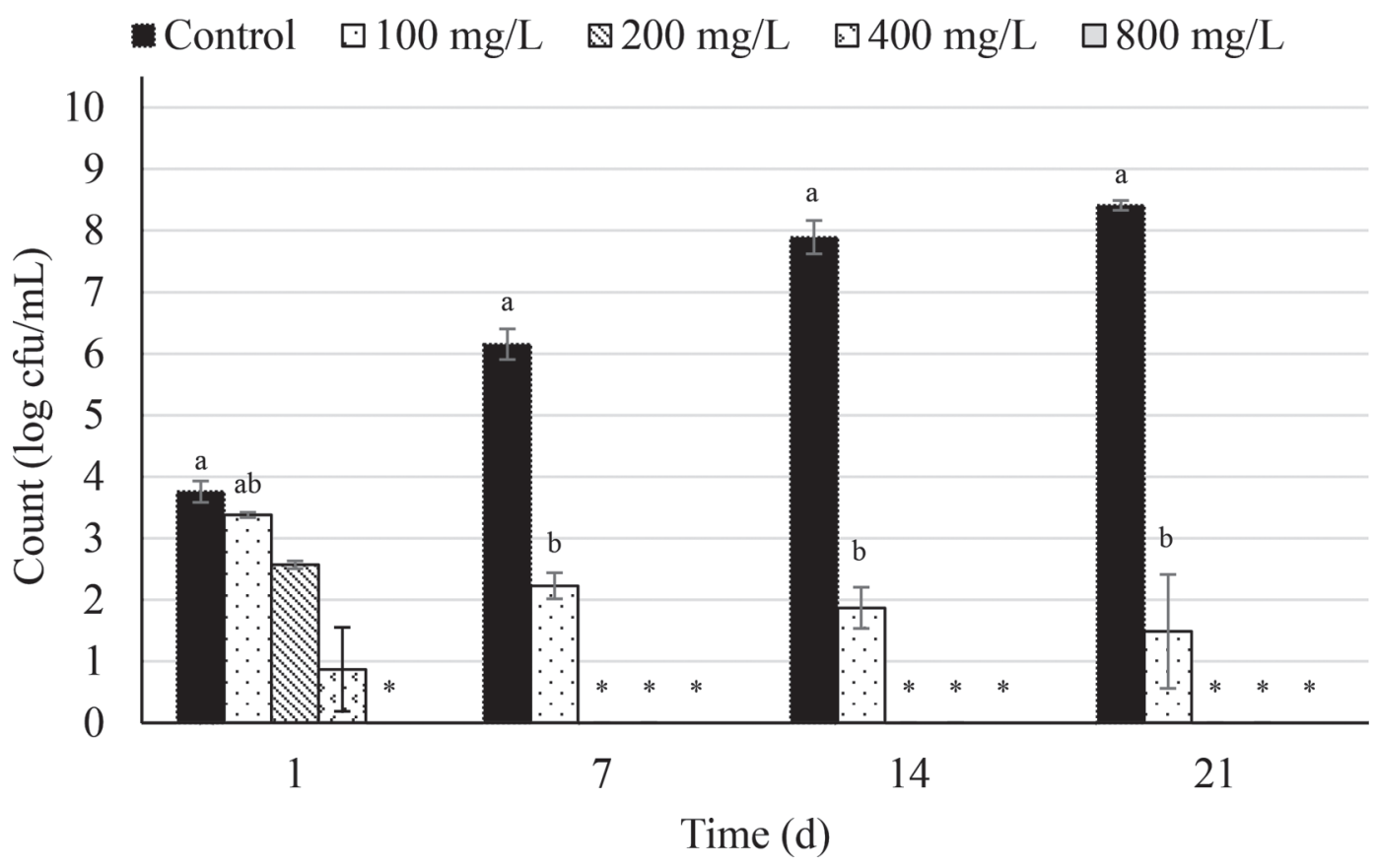

Figure 5. Change in Listeria monocytogenes counts (mean $\log _{10} \mathrm{cfu} / \mathrm{mL}$ of 3 replicates $\pm \mathrm{SEM}$ ) in sterile whole milk with hydrogen peroxide when held at $7^{\circ} \mathrm{C}$. Columns with different letters within a time point differ $(P<0.05)$. * Mean counts below the limit of detection of $\geq 1 \mathrm{cfu} / \mathrm{mL}$ for all 3 biological replicates. Treatments at 200, 400, and $800 \mathrm{mg} / \mathrm{L}$ were not included in statistical analyses.

thereby potentially limiting its use in the production of cultured dairy products. Oxidative rancidity has also been known to occur when adding HP to foods with high fat content (Wambura and Yang, 2011) due to free radical production. Therefore, additional studies are needed to investigate the rate of pathogen inactivation within the first $24 \mathrm{~h}$ of treatment, the effect of catalase neutralization on the antimicrobial activity against $L$. monocytogenes populations, and potential lipid oxidation in milk and dairy products.

\section{Efficacy of Antimicrobials in Combination}

Combinations of antimicrobials added at $0.5 \times$ their individual inhibitory concentrations in whole milk were evaluated to identify antagonistic, indifferent, additive, and synergistic effects (Ma et al., 2013). Effective combinatorial treatments allow for reductions in use concentrations for individual antimicrobials to help alleviate potential limitations posed by cost and effects on organoleptic properties of foods. Data on the combination of antimicrobials in milk are generally limited to bacteriocins and plant-derived antimicrobials (Singh et al., 2001; Cava et al., 2007; López-Expósito et al., 2008; Ma et al., 2013). For example, Ma et al. (2013) reported synergistic antilisterial activity when combining thymol $(3,000 \mathrm{mg} / \mathrm{L})$ with LAE $(375 \mathrm{mg} / \mathrm{L})$ in $2 \%$ reduced fat milk at $21^{\circ} \mathrm{C}$. Previous research in nutrient broth has demonstrated synergistic inactivation of $L$. monocytogenes at $\mathrm{pH} 7.4$ using various combinations of EPL and LAE at comparably low concentrations, suggesting this combination as a potential candidate for use in milk and other low acid foods (Kozak et al., 2017). The combination of EPL and LAE in milk in the present study was inhibitory through $7 \mathrm{~d}$, after which counts increased to $7.4 \pm 0.28 \log _{10} \mathrm{cfu} / \mathrm{mL}$ by $21 \mathrm{~d}$ (Figure 6 ). These counts were not different $(P=1)$ than the most effective constituent alone (LAE at $400 \mathrm{mg} / \mathrm{L}$; Table 3), suggesting the combination was indifferent. Similarly, $\mathrm{EPL}+\mathrm{CA}$ combination treatments in milk at $7^{\circ} \mathrm{C}$ were inhibitory through $7 \mathrm{~d}$ (Figure 6) after which counts increased to levels that did not differ $(P=1)$ from $\mathrm{CA}$ alone at 1,600 $\mathrm{mg} / \mathrm{L}$ at d 21 (Table 3 ), suggesting indifference as well. This is in contrast to observations in broth where the combination of EPL $+\mathrm{CA}$ worked synergistically to inactivate $L$. monocytogenes at $\mathrm{pH}$ 5.5 with additive interactions for pathogen inhibition and inactivation at $\mathrm{pH} 7.4$ (Kozak et al., 2017). The combination of LAE + SC limited L. monocytogenes growth to $1.21 \log _{10} \mathrm{cfu} / \mathrm{mL}$ higher than initial inoculum and $2.29 \mathrm{cfu} / \mathrm{mL}$ lower than control at $21 \mathrm{~d}$ (Figure 6 ). Counts resulting from the combination treatment in milk at $21 \mathrm{~d}(5.84 \pm 0.01 \mathrm{cfu} / \mathrm{mL})$ were significantly lower than LAE alone at $400 \mathrm{mg} / \mathrm{L}(P=0.025 ; 8.21$ 
$\log _{10} \mathrm{cfu} / \mathrm{mL}$; Table 3) but not SC alone at $1600 \mathrm{mg} / \mathrm{L}$ $\left(P=0.9 ; 6.59 \log _{10} \mathrm{cfu} / \mathrm{mL}\right.$; Table 3$)$. Because the difference in counts between the most active constituent (SC at 1,600 mg/L; Table 3) and the combination was $<1 \log _{10} \mathrm{cfu} / \mathrm{mL}$, the combination was characterized as indifferent. The combination of EPL $+\mathrm{SC}$, which has demonstrated bactericidal synergy in broth at $\mathrm{pH}$ 5.5 and 7.4 (Kozak et al., 2017), was the most effective combination tested, reducing L. monocytogenes populations in milk by $>1 \log _{10} \mathrm{cfu} / \mathrm{mL}$ to a final count of 3.56 $\pm 0.59 \log _{10} \mathrm{cfu} / \mathrm{mL}$ (Figure 6 ) at $21 \mathrm{~d}$. With a $>3 \log _{10}$ $\mathrm{cfu} / \mathrm{mL}$ difference in counts at $21 \mathrm{~d}$ between the combination treatment and the most active constituent alone $\left(P<0.001 ;\right.$ SC at $6.59 \pm 0.21 \log _{10} \mathrm{cfu} / \mathrm{mL}$; Table 3$)$ the combination was defined as synergistic. The combination also inhibited growth to counts similar to $\mathrm{SC}$ or EPL alone at their inhibitory concentrations $(3,200$ and $100 \mathrm{mg} / \mathrm{L}$, respectively; Figures 2 and 4, respectively) through $21 \mathrm{~d}$, highlighting the ability of synergistic combinations to reduce individual use concentrations without diminishing overall antimicrobial efficacy.

\section{CONCLUSIONS}

The focus of this study was to determine the efficacy of antimicrobials to control L. monocytogenes in whole milk. Overall, concentrations of LAE $(800 \mathrm{mg} / \mathrm{L})$ and EPL (100-400 mg/L), as well as SC and CA (3200 $\mathrm{mg} / \mathrm{L}$ each) capable of inhibiting L. monocytogenes growth in whole milk over $21 \mathrm{~d}$ at $7^{\circ} \mathrm{C}$ were identified. The addition of EPL at $800 \mathrm{mg} / \mathrm{L}$ reduced L. monocytogenes counts by more than $3 \log _{10} \mathrm{cfu} / \mathrm{mL}$ from initial inoculation levels after $21 \mathrm{~d}$. Addition of HP to milk at 400 and $800 \mathrm{mg} / \mathrm{L}$ was bactericidal within $24 \mathrm{~h}$, whereas $200 \mathrm{mg} / \mathrm{L}$ reduced counts by $>3 \log _{10} \mathrm{cfu} / \mathrm{mL}$ from initial inoculation levels by d 7. Although combinatorial treatments containing EPL $+\mathrm{CA}, \mathrm{EPL}+\mathrm{LAE}$, and $\mathrm{LAE}+\mathrm{SC}$ were characterized as indifferent, $\mathrm{EPL}+\mathrm{SC}$ was characterized as synergistic, allowing for reductions in individual use concentrations while achieving similar pathogen inhibition. Considering the initial pathogen levels in the present study are higher than would be expected, these results indicate even greater potential for effective L. monocytogenes control. Overall, these data identify effective antilisterial treatments in milk and serve as a foundation for the continued development of antimicrobial treatments to control L. monocytogenes in dairy products. Surface applications are not expected to affect native microbiota, but further studies are necessary if antimicrobials are to be used in the manufacture of cultured products or in raw milk to determine the effect on desirable microbiota. Considering concentrations of antimicrobials to effectively control pathogens in dairy products will vary based on 
Table 3. Difference in mean counts $\left(\log _{10} \mathrm{cfu} / \mathrm{mL}\right)$ between combinatory antimicrobial treatments and their individual constituents at $\mathrm{d} 21^{1}$

\begin{tabular}{|c|c|c|c|c|}
\hline \multirow[b]{2}{*}{ Treatment } & \multicolumn{4}{|c|}{ Difference in mean counts (combination - constituent) at d 21} \\
\hline & EPL & $\mathrm{SC}$ & $\mathrm{CA}$ & LAE \\
\hline $\begin{array}{l}\mathrm{EPL}+\mathrm{SC} \\
\mathrm{CA}+\mathrm{EPL} \\
\mathrm{LAE}+\mathrm{SC} \\
\mathrm{EPL}+\mathrm{LAE}\end{array}$ & $\begin{array}{l}-4.82^{* * *} \\
-1.23 \\
-0.98\end{array}$ & $\begin{array}{l}-3.03^{* * *} \\
-0.75\end{array}$ & 0.22 & $\begin{array}{l}-2.37^{*} \\
-0.81\end{array}$ \\
\hline
\end{tabular}

${ }^{1} \mathrm{CA}=$ caprylic acid $(1,600 \mathrm{mg} / \mathrm{L}) ; \mathrm{EPL}=\varepsilon$-polylysine $(50 \mathrm{mg} / \mathrm{L}) ; \mathrm{LAE}=$ lauric arginate $(400 \mathrm{mg} / \mathrm{L}) ; \mathrm{SC}=$ sodium caprylate $(1,600 \mathrm{mg} / \mathrm{L})$. Counts for combinatory antimicrobial treatments and their individual constituents at d 21 are also depicted in Figures 1 to 6.

*Counts between combination and single antimicrobial treatment differ at $P<0.05$.

***Counts between combination and single antimicrobial treatment differ at $P<0.001$.

product composition, the presence of additional inhibitors, and so on, and that the perception of off flavors and odors will differ between products, future studies will be needed to evaluate potential changes to the sensory properties of products containing antimicrobials at effective concentrations to ensure consumer acceptance. Although many antimicrobials are GRAS for use in milk and other dairy products including cheese, products formulated with these and other antimicrobials discussed herein may not meet the current standards of identity. The continued identification and development of process controls for foodborne pathogens suggests revisions to the Standards of Identity to include anti- microbial applications with demonstrated efficacy and safety are warranted.

\section{ACKNOWLEDGMENTS}

This project was supported by the National Dairy Council (Rosemont, IL) and the United States Department of Agriculture (USDA) National Institute of Food and Agriculture (NIFA, Washington, DC), Multistate project S1056. Any opinions, findings, conclusions, or recommendations expressed in this manuscript are those of the author(s) and do not necessarily reflect the view of the NIFA, the USDA, or any other sponsors.

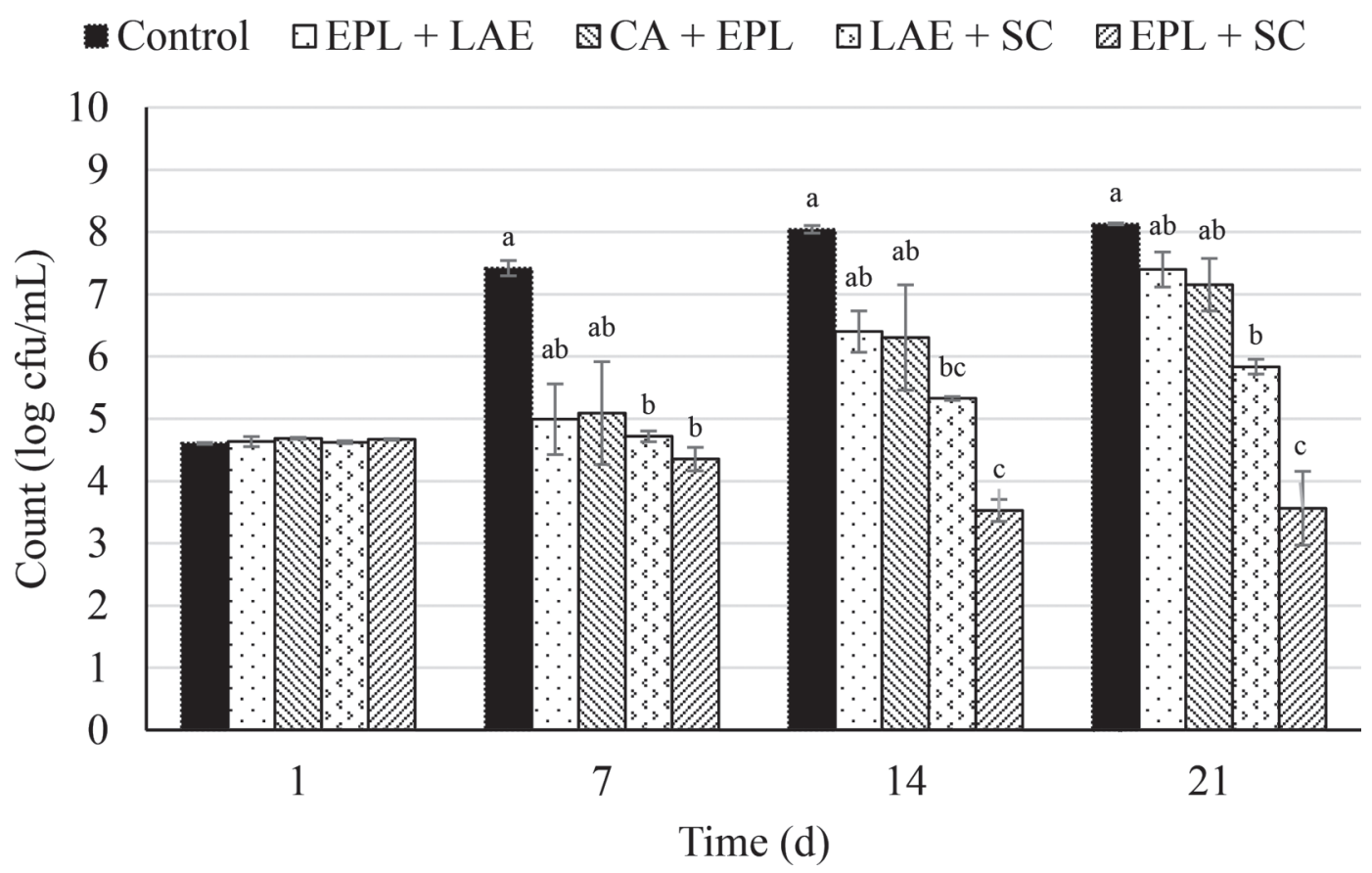

Figure 6. Change in Listeria monocytogenes counts (mean $\log _{10} \mathrm{cfu} / \mathrm{mL}$ of 3 replicates $\pm \mathrm{SEM}$ ) in sterile whole milk with antimicrobials added in combination when held at $7^{\circ} \mathrm{C} . \mathrm{CA}=$ caprylic acid $(1,600 \mathrm{mg} / \mathrm{L}) ; \mathrm{EPL}=\varepsilon$-polylysine $(50 \mathrm{mg} / \mathrm{L}) ; \mathrm{LAE}=$ lauric arginate $(400 \mathrm{mg} / \mathrm{L})$; $\mathrm{SC}=$ sodium caprylate $(1,600 \mathrm{mg} / \mathrm{L})$. Columns with different letters within a time point differ $(P<0.05)$. 


\section{REFERENCES}

Almeida, G., R. Magalhães, L. Carneiro, I. Santos, J. Silva, V. Ferreira, T. Hogg, and P. Teixeira. 2013. Foci of contamination of Listeria monocytogenes in different cheese processing plants. Int. J. Food Microbiol. 167:303-309.

Amrouche, T., K. S. Noll, Y. Wang, Q. Huang, and M. L. Chikindas. 2010. Antibacterial activity of subtilosin alone and combined with curcumin, poly-lysine and zinc lactate against Listeria monocytogenes strains. Probiotics Antimicrob. Proteins 2:250-257.

Andrews, J. M. 2001. Determination of minimum inhibitory concentrations. J. Antimicrob. Chemother. 48:5-16.

Batz, M. B., S. Hoffmann, and J. G. Morris Jr. 2012. Ranking the disease burden of 14 pathogens in food sources in the United States using attribution data from outbreak investigations and expert elicitation. J. Food Prot. 75:1278-1291.

Bonnaud, M., J. Weiss, and D. J. McClements. 2010. Interaction of a food-grade cationic surfactant (lauric arginate) with food-grade biopolymers (pectin, carrageenan, xanthan, alginate, dextran, and chitosan). J. Agric. Food Chem. 58:9770-9777.

Cava, R., E. Nowak, A. Taboada, and F. Marin-Iniesta. 2007. Antimicrobial activity of clove and cinnamon essential oils against Listeria monocytogenes in pasteurized milk. J. Food Prot. 70:2757-2763.

Centers for Disease Control and Prevention (CDC). 2017. Foodborne Outbreak Online Database (FOOD Tool). Accessed Nov. 16, 2017. https://www.cdc.gov/foodborneoutbreaks/.

Chen, H., and Q. Zhong. 2017. Lactobionic acid enhances the synergistic effect of nisin and thymol against Listeria monocytogenes Scott A in tryptic soy broth and milk. Int. J. Food Microbiol. 260:36-41.

Dominguez, L., J. F. Garayazabal, E. R. Ferri, J. A. Vazquez, E. Gomez-Lucia, C. Ambrosio, and G. Suarez. 1987. Viability of Listeria monocytogenes in milk treated with hydrogen peroxide. J. Food Prot. 50:636-639.

European Food Safety Authority (EFSA). 2007. Opinion of the scientific panel on food additives, flavourings, processing aids and materials in contact with food on a request from the commission related to an application on the use of ethyl lauroyl arginate as a food additive. EFSA J. 511:1-27.

Food and Drug Administration (FDA). 2005a. Agency response letter GRAS notice no. GRN 000164. Accessed May 24, 2017. https:// www.fda.gov/Food/IngredientsPackagingLabeling/GRAS/ NoticeInventory/ucm154571.htm.

Food and Drug Administration (FDA). 2005b. GRAS notice no. GRN 000164. Accessed Oct. 10, 2017. https://www.fda.gov/downloads/ Food/IngredientsPackagingLabeling/GRAS/NoticeInventory/ UCM268847.

Food and Drug Administration (FDA). 2011. Agency response letter GRAS notice no. GRN 000336. Accessed Nov. 14, 2016. http://www.fda.gov/Food/IngredientsPackagingLabeling/GRAS/ NoticeInventory/ucm271325.htm.

Food and Drug Administration (FDA). 2015. Select Committee on GRAS Substances Database. Accessed May 24, 2017. https://www .accessdata.fda.gov/scripts/fdcc/?set=SCOGS.

Food and Drug Administration (FDA). 2016. Code of Federal Regulations. Title 21, Chapter I, Subchapter B, Part 133. Accessed May 24, 2017. https://www.accessdata.fda.gov/scripts/cdrh/cfdocs/ cfcfr/cfrsearch.cfm?cfrpart $=133$.

Food and Drug Administration (FDA). 2017a. Code of Federal Regulations. Title 21, Chapter I, Subchapter B, Part 184. Accessed Oct. 9, 2017. https://www.accessdata.fda.gov/scripts/cdrh/cfdocs/ cfcfr/CFRSearch.cfm?fr $=184.1025$.

Food and Drug Administration (FDA). 2017b. Draft Guidance for Industry: Control of Listeria monocytogenes in ReadyTo-Eat Foods. Accessed Jul. 17, 2017. https://www.fda.gov/ RegulatoryInformation/Guidances/ucm073110.htm.

Gadotti, C., L. Nelson, and F. Diez-Gonzalez. 2014. Inhibitory effect of combinations of caprylic acid and nisin on Listeria monocytogenes in queso fresco. Food Microbiol. 39:1-6.

Gaya, P. I., M. A. Medina, and M. A. Nuñez. 1991. Effect of the lactoperoxidase system on Listeria monocytogenes behavior in raw milk at refrigeration temperatures. Appl. Environ. Microbiol. $57: 3355-3360$.

Gaysinsky, S., T. M. Taylor, P. M. Davidson, B. D. Bruce, and J. Weiss. 2007. Antimicrobial efficacy of eugenol microemulsions in milk against Listeria monocytogenes and Escherichia coli O157: H7. J. Food Prot. 70:2631-2637.

Geornaras, I., and J. N. Sofos. 2005. Activity of $\varepsilon-$ polylysine against Escherichia coli O157:H7, Salmonella Typhimurium, and Listeria monocytogenes. J. Food Sci. 72:M404-M408.

Geornaras, I., Y. Yoon, K. E. Belk, G. C. Smith, and J. N. Sofos. 2007. Antimicrobial activity of $\varepsilon$-polylysine against Escherichia coli O157:H7, Salmonella Typhimurium, and Listeria monocytogenes in various food extracts. J. Food Sci. 72:M330-M334.

Hiraki, J., T. Ichikawa, S. I. Ninomiya, H. Seki, K. Uohama, H. Seki, and J. W. Barnett Jr.. 2003. Use of ADME studies to confirm the safety of e-polylysine as a preservative in food. Regul. Toxicol. Pharmacol. 37:328-340.

Kabara, J. J., D. M. Swieczkowski, A. J. Conley, and J. P. Truant. 1972. Fatty acids and derivatives as antimicrobial agents. Antimicrob. Agents Chemother. 2:23-28.

Kennedy, J., V. Jackson, I. S. Blair, D. A. Mc, C. Dowell, C. Cowan, and D. J. Bolton. 2005. Food safety knowledge of consumers and the microbiological and temperature status of their refrigerators. J. Food Prot. 68:1421-1430.

Kozak, S. M., K. M. Margison, and D. J. D'Amico. 2017. Synergistic antimicrobial combinations inhibit and inactivate Listeria monocytogenes in neutral and acidic broth systems. J. Food Prot. 80:1266-1272.

Lingbeck, J. M., P. Cordero, C. A. O'Bryan, M. G. Johnson, S. C Ricke, and P. G. Crandall. 2014. Temperature effects on the antimicrobial efficacy of condensed smoke and lauric arginate against Listeria and Salmonella. J. Food Prot. 77:934-940.

Liu, Y., and A. Ream. 2008. Gene expression profiling of Listeria monocytogenes strain F2365 during growth in ultra-high-temperature-processed skim milk. Appl. Environ. Microbiol. 74:6859-6866.

López-Expósito, I., A. Pellegrini, L. Amigo, and I. Recio. 2008. Synergistic effect between different milk-derived peptides and proteins. J. Dairy Sci. 91:2184-2189.

Lourenço, A., M. B. Kamnetz, C. Gadotti, and F. Diez-Gonzalez. 2017. Antimicrobial treatments to control Listeria monocytogenes in queso fresco. Food Microbiol. 64:47-55.

Luchansky, J. B., J. E. Call, B. Hristova, L. Rumery, L. Yoder, and A. Oser. 2005. Viability of Listeria monocytogenes on commerciallyprepared hams surface treated with acidic calcium sulfate and lauric arginate and stored at $4^{\circ} \mathrm{C}$. Meat Sci. 71:92-99.

Ma, Q., P. M. Davidson, and Q. Zhong. 2013. Antimicrobial properties of lauric arginate alone or in combination with essential oils in tryptic soy broth and $2 \%$ reduced fat milk. Int. J. Food Microbiol. 166:77-84.

Ma, Y., C. Ryan, D. M. Barbano, D. M. Galton, M. A. Rudan, and K. J. Boor. 2000. Effects of somatic cell count on quality and shelf-life of pasteurized fluid milk. J. Dairy Sci. 83:264-274.

Martin, N. H., A. Friedlander, A. Mok, D. Kent, M. Wiedmann, and K. J. Boor. 2014. Peroxide test strips detect added hydrogen peroxide in raw milk at levels affecting bacterial load. J. Food Prot. 77:1809-1813

Nair, M. K. M., P. Vasudevan, T. Hoagland, and K. Venkitanarayanan. 2004. Inactivation of Escherichia coli O157:H7 and Listeria monocytogenes in milk by caprylic acid and monocaprylin. Food Microbiol. 21:611-616

National Advisory Committee on Microbiological Criteria for Foods (NACMCF). 2010. Parameters for determining inoculated pack/ challenge study protocols. J. Food Prot. 73:140-202.

NCCLS. 1999. Methods for determining bactericidal activity of antimicrobial agents; approved guideline. Document M26-A. National Committee for Clinical Laboratory Standards, Wayne, PA.

Nuñez de Gonzalez, M. T., J. T. Keeton, and L. J. Ringer. 2006 Sensory and physicochemical characteristics of frankfurters containing lactate with antimicrobial surface treatments. J. Food Sci. 69:S221-S228 
Rodriguez, E., J. Seguer, X. Rocabayera, and A. Manresa. 2004. Cellular effects of monohydrochloride of l-arginine, No-lauroyl ethylester (LAE) on exposure to Salmonella typhimurium and Staphylococcus aureus. J. Appl. Microbiol. 96:903-912.

Romanova, N., S. Favrin, and M. W. Griffiths. 2002. Sensitivity of Listeria monocytogenes to sanitizers used in the meat processing industry. Appl. Environ. Microbiol. 68:6405-6409.

Roundy, Z. D. 1958. Treatment of milk for cheese with hydrogen peroxide. J. Dairy Sci. 41:1460-1465.

Shah, B., P. M. Davidson, and Q. Zhong. 2013. Nanodispersed eugenol has improved antimicrobial activity against Escherichia coli O157: $\mathrm{H} 7$ and Listeria monocytogenes in bovine milk. Int. J. Food Microbiol. 161:53-59.

Shi, C., X. Zhao, R. Meng, Z. Liu, G. Zhang, and N. Guo. 2017. Synergistic antimicrobial effects of nisin and p-Anisaldehyde on Staphylococcus aureus in pasteurized milk. Lebensm. Wiss. Technol. 84:222-230.

Shima, S., H. Matsuoka, T. Iwamoto, and H. Sakai. 1984. Antimicrobial action of $\varepsilon$-poly-L-lysine. J. Antibiot. (Tokyo) 37:1449-1455.

Singh, B., M. B. Falahee, and M. R. Adams. 2001. Synergistic inhibition of Listeria monocytogenes by nisin and garlic extract. Food Microbiol. 18:133-139.
Siragusa, G. R., and M. G. Johnson. 1989. Inhibition of Listeria monocytogenes growth by the lactoperoxidase-thiocyanate- $\mathrm{H} 2 \mathrm{O} 2$ antimicrobial system. Appl. Environ. Microbiol. 55:2802-2805.

Smith, T. J., E. A. Foegeding, and M. Drake. 2015. Sensory and functionality differences of whey protein isolate bleached by hydrogen or benzoyl peroxide. J. Food Sci. 80:C2153-C2160.

Soni, K. A., R. Nannapaneni, M. W. Schilling, and V. Jackson. 2010. Bactericidal activity of lauric arginate in milk and Queso Fresco cheese against Listeria monocytogenes cold growth. J. Dairy Sci. 93:4518-4525.

Steenbergen, J. N., J. F. Mohr, and G. M. Thorne. 2009. Effects of daptomycin in combination with other antimicrobial agents: a review of in vitro and animal model studies. J. Antimicrob. Chemother. 64:1130-1138.

Subramanian, C. S., and N. F. Olson. 1968. Effect of hydrogen peroxide on activity of lactic cultures in milk. J. Dairy Sci. 51:517-519.

Wambura, P., and W. Yang. 2011. Influence of power ultrasound on oxidative rancidity of potato chips. Food Process Eng. 34:10461052.

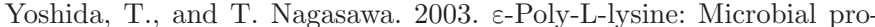
duction, bio-degradation and application potential. Appl. Microbiol. Biotechnol. 62:21-26. 